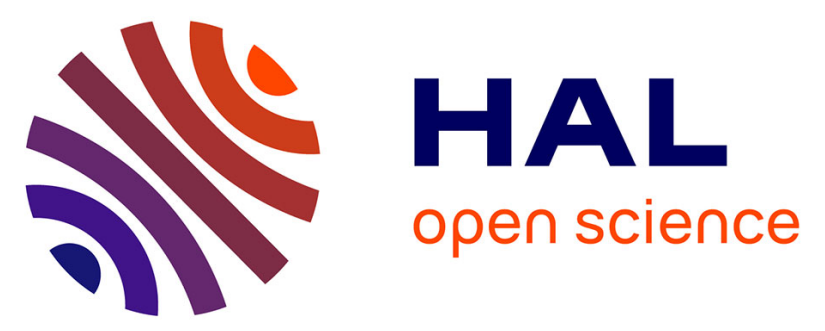

\title{
Si and Ge allotrope heterostructured nanowires: experimental evaluation of the thermal conductivity reduction
}

\author{
Aymen Ben Amor, Doriane Djomani, Mariam Fakhfakh, Stefan Dilhaire, \\ Laetitia Vincent, Stéphane Grauby
}

\section{To cite this version:}

Aymen Ben Amor, Doriane Djomani, Mariam Fakhfakh, Stefan Dilhaire, Laetitia Vincent, et al.. Si and Ge allotrope heterostructured nanowires: experimental evaluation of the thermal conductivity reduction. Nanotechnology, 2019, 30 (37), pp.375704. 10.1088/1361-6528/ab29a6 . hal-02174973

\section{HAL Id: hal-02174973 https://hal.science/hal-02174973}

Submitted on 5 Jul 2019

HAL is a multi-disciplinary open access archive for the deposit and dissemination of scientific research documents, whether they are published or not. The documents may come from teaching and research institutions in France or abroad, or from public or private research centers.
L'archive ouverte pluridisciplinaire HAL, est destinée au dépôt et à la diffusion de documents scientifiques de niveau recherche, publiés ou non, émanant des établissements d'enseignement et de recherche français ou étrangers, des laboratoires publics ou privés. 
ACCEPTED MANUSCRIPT

\section{Si and Ge allotrope heterostructured nanowires: experimental evaluation of the thermal conductivity reduction}

To cite this article before publication: Aymen Ben Amor et al 2019 Nanotechnology in press https://doi.org/10.1088/1361-6528/ab29a6

\section{Manuscript version: Accepted Manuscript}

Accepted Manuscript is "the version of the article accepted for publication including all changes made as a result of the peer review process, and which may also include the addition to the article by IOP Publishing of a header, an article ID, a cover sheet and/or an 'Accepted Manuscript' watermark, but excluding any other editing, typesetting or other changes made by IOP Publishing and/or its licensors"

This Accepted Manuscript is @ 2019 IOP Publishing Ltd.

During the embargo period (the 12 month period from the publication of the Version of Record of this article), the Accepted Manuscript is fully protected by copyright and cannot be reused or reposted elsewhere.

As the Version of Record of this article is going to be / has been published on a subscription basis, this Accepted Manuscript is available for reuse under a CC BY-NC-ND 3.0 licence after the 12 month embargo period.

After the embargo period, everyone is permitted to use copy and redistribute this article for non-commercial purposes only, provided that they adhere to all the terms of the licence https://creativecommons.org/licences/by-nc-nd/3.0

Although reasonable endeavours have been taken to obtain all necessary permissions from third parties to include their copyrighted content within this article, their full citation and copyright line may not be present in this Accepted Manuscript version. Before using any content from this article, please refer to the Version of Record on IOPscience once published for full citation and copyright details, as permissions will likely be required. All third party content is fully copyright protected, unless specifically stated otherwise in the figure caption in the Version of Record.

View the article online for updates and enhancements. 


\title{
Si and Ge allotrope heterostructured nanowires: experimental evaluation of the thermal
} conductivity reduction

Aymen Ben Amor ${ }^{1}$, Doriane Djomani ${ }^{2}$, Mariam Fakhfakh ${ }^{2}$, Stefan Dilhaire ${ }^{1}$, Laetitia

\author{
Vincent $^{2}$, and Stéphane Grauby ${ }^{1, *}$ \\ ${ }^{1}$ Univ. Bordeaux, LOMA, CNRS UMR 5798, F-33400 Talence, France. \\ ${ }^{2}$ C2N - CNRS, Univ. Paris-Sud, Université Paris Saclay, 91405 Orsay, France. \\ *corresponding author : stephane.grauby@u-bordeaux.fr
}

\begin{abstract}
We have studied the thermal conductivity of Ge and Si allotrope heterostructured nanowires (NWs) synthesized by phase transformation. The NWs are composed of successive hexagonal $2 \mathrm{H}$ and cubic diamond $3 \mathrm{C}$ crystal phase along the $<111>$ axis. Using $3 \omega-\mathrm{SThM}$ (Scanning Thermal Microscopy) on NWs embedded in a silica matrix, we present the first experimental evidence of thermal conductivity reduction in such allotrope $2 \mathrm{H} / 3 \mathrm{C}$ heterostructured NWs.

In Ge heterostructured 2H/3C NWs, similarly to homogeneous 3C NWs, we show a thermal conductivity reduction when the NW diameter decreases. In addition, in Si and Ge NWs, we observe a reduced thermal conductivity due to the heterostructuration $2 \mathrm{H} / 3 \mathrm{C}$.

We evidence that the temperature of phase transformation, which influences the size and the number of $2 \mathrm{H}$ domains, can constitute an efficient parameter to tune the thermal conductivity.
\end{abstract}

Keywords: thermal conductivity, allotrope heterostructured nanowires, Germanium, Silicium 


\section{INTRODUCTION}

The main promising strategy for optimising thermoelectric power of current materials stands in nanostructuration providing the possibility to independently reduce the thermal conductivity without affecting the electrical conductivity [1]. This can be the case for nanostructured materials for which at least one dimension is smaller than the phonon mean free path and larger than the electron mean free path: they hence behave as phonon glasses and electron crystals[2]. As a consequence, one-dimensional systems such as nanowires (NWs) can be very good candidates for thermoelectric applications.

In particular, group IV semiconductors (Si, Ge, SiGe) are widely studied since devices could take advantages on abundant non-toxic material and Si-compatible technology on one side and on good thermoelectric properties on the other side. For these materials, the phonon mean free path at room temperature is classically around a few hundred nanometers while the electron mean free path is only a few nanometers. Then, NWs with diameters between 20 and $200 \mathrm{~nm}$ are of prime interest. For instance, the ZT of Si in bulk is lower than 0.01 at $300 \mathrm{~K}$, and reaches around 0.5-0.6 in 20-200 nm diameter Si NWs [3,4]. The 1D-shape enhances the influence of surface and allows the combination of different materials (such as SiGe lattices) both reducing drastically the thermal conductivity. Indeed NWs are promising nanostructures for thermoelectricity and they can be advantageously integrated in thermoelectric generators based on vertical NW arrays [5,6].

Another route of nanostructuration is the formation of polytype heterostructures within the NWs. In [7], the authors have synthesized twin superlattices in GaP NWs via VLS growth mechanism and shown that both chemical potential and surface energies are key parameters in determining the twin density. In the case of Si or Ge NWs, the polytype synthesis cannot be obtained during the growth. Indeed, recently we have developed an original method based on top-down etching to achieve phase transformation in Si and Ge nanowires under external 
stress [8,9]. <111>-oriented NWs with standard diamond structure 3C undergo a phase transformation toward the $2 \mathrm{H}$ hexagonal phase. The phase transformation occurs heterogeneously along the length of the NW resulting in a quasi-periodic superlattice of $3 \mathrm{C} / 2 \mathrm{H}$ heterostructures with abrupt interfaces along the NWs. The structure is stable at least up to $600^{\circ} \mathrm{C}$. As the heterostructuration is not performed during growth but by phase transformation after the nanowire top down etching, we point out that the orientation relationship between the $3 \mathrm{C}$ and $2 \mathrm{H}$ bands is $[1-10] 3 \mathrm{C} / /[-2110] 2 \mathrm{H}$ and $(110) 3 \mathrm{C} / /(0001) 2 \mathrm{H}$. It is clearly not the usual one obtained by VLS growth for III/V nanowires for instance that is (111)3C//(0001)2H.

According to theoretical calculations, these novel axial allotrope heterostructures could provide substantial benefits for phonon dispersion. The first calçulations of phonon transport performed by PBTE (first-principle-based Peierls-Boltzmann transport equation) indicate a reduction by a factor of 2 of the thermal conductivity in Si-2H with respect to Si-3C [10]. On the other hand, the presence of structural discontinuities $2 \mathrm{H} / 3 \mathrm{C}$ in a chemically homogeneous Ge NW is expected to reduce the thermal conductance [11].

To experimentally evaluate the thermal conductivity of NWs, most measurements are performed using microfabricated suspended devices providing an heat source and an heat $\operatorname{sink}[12,13]$. This configuration enables the three parameters (Seebeck coefficient S, electrical conductivity $\sigma$ and thermal conductivity $\lambda$ ) involved in the ZT figure of merit to be evaluated at the same time $[3,13,14]$. Moreover, the measurements with this type of microfabricated devices can be performed over a wide range of temperature providing access to the underlying physics. But it is worth mentioning that this technique measures the thermal conductivity of one isolated NW which can be quite different from the thermal conductivity of the NWs embedded in the matrix, which constitutes the effective functioning device, because of the 
matrix/NWs interaction[15]. In addition the fabrication of the device to be characterized requires many heavy processing steps that may deteriorate and/or contaminate the NW.

Another approach consists in using an Atomic Force Microscope equipped with a temperature sensor, either a thermocouple or a thermoresistive tip. This technique is called Scanning Thermal Microscopy (SThM) and enables to do temperature or thermal conductivity imaging[16-18]. In our case, we have developed an experimental set-up using SThM with a thermoresistive tip which operates in an active regime called $3 \omega$-SThM (Scanning Thermal Microscopy). It allows to record thermal images of individual NWs with a $100 \mathrm{~nm}$ typical thermal spatial resolution and a $10 \mathrm{~nm}$ typical topographical spatial resolution. This technique has the advantage to thermally probe a wide range of individual NWs embedded in their matrix in a few minutes. We can hence deduce a mean/thermal conductivity of the NWs by a statistical data processing.

In this paper, we first recall, in section II, the experimental procedure including sample fabrication, principle of the measurement set-up as well as the experimental conditions and limitations. Then, we present thermal conductivity measurements of $<111>$ oriented $3 \mathrm{C} / 2 \mathrm{H}$ heterostructured NWs obtained by top-down etching and processed for polytype heterostructuration, as described in $[8,9]$. Let us underline that no phase transformation was observed with other crystallographic orientations. The first investigated heterostructured NWs, presented in section III, are Ge NWs with various diameters decreasing from $460 \mathrm{~nm}$ to $220 \mathrm{~nm}$. Then, in section IV, we have studied Si heterostructured NWs processed with various annealing temperature, which influences the number and size of the $2 \mathrm{H}$ domains. For both kinds of NWs, their thermal conductivity is evaluated and compared with bulk and non heterostructured NWs.

\section{EXPERIMENTAL METHODOLOGY}


The thermal conductivity measurements are performed by using SThM (Scanning Thermal Microscopy) in a 3 3 -method configuration [16,19] at room temperature. The geometrical configuration is sketched in figure 1 . The employed tip is a commercial $\mathrm{Pd} / \mathrm{SiN}$ thermo-resistive probe to carry out thermal images while simultaneously obtaining contact mode topography images. It is made of a thin Palladium (Pd) ribbon on a $1 \mu \mathrm{m}$ thick SiN silica layer. The thin Pd ribbon acts as the thermo-resistive element. The tip characteristics are summed up in Table 1: resistance $\mathrm{R}_{0}$ at room temperature, temperature coefficient $\alpha_{\text {Tip }}$, length $\mathrm{L}_{\text {Tip }}$, width $\mathrm{l}_{\text {Tip }}$, cut-off thermal frequency $\mathrm{f}_{\mathrm{Tip}}$ and thermal exchange radius $\mathrm{b}$. The thermal exchange radius, which limits the thermal spatial resolution, is evaluated experimentally[20]. For each tip parameter, a range is given since these characteristics vary from one tip to another.

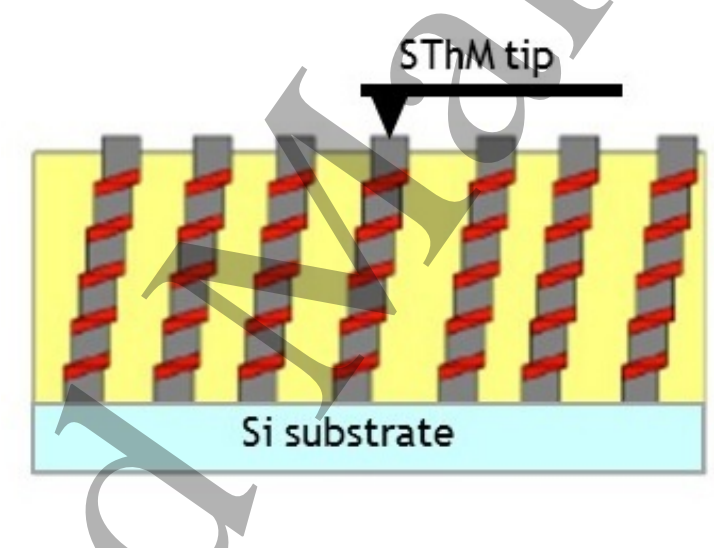

Figure 1: Schematic view of the sample and measurement principle: the $<111>$ NWs are grown by top-down etching, then spin coated in HSQ resist which transforms into $\mathrm{SiO}_{2}$ after annealing. The HSQ ensures the phase transformation and the mechanical handling. Red zones along the NWs represent $2 \mathrm{H}$ domains. No transformation could be observed for other crystallographic orientations. The SThM thermoresistive tip scans the surface of the sample. It generates a heat flux on top of the NWs which propagates along them. 


\begin{tabular}{|l|l|l|l|l|l|}
\hline $\mathrm{R}_{0}(\Omega)$ & $\alpha_{\text {Tip }}\left(\mathrm{K}^{-1}\right)$ & $\mathrm{L}_{\text {Tip }}(\mu \mathrm{m})$ & $\mathrm{l}_{\text {Tip }}(\mu \mathrm{m})$ & $\mathrm{f}_{\text {Tip }}(\mathrm{kHz})$ & $\mathrm{b}(\mathrm{nm})$ \\
\hline $300-400$ & $1-2 \times 10^{-3}$ & $8-10$ & $1-2$ & $3-5$ & $70-300$ \\
\hline
\end{tabular}

Table 1. Pd thermoresitive tip characteristics

The tip is used in an active regime, which means that it is at the same time the heater and the sensor. Indeed, a $\omega$ pulsation sinusoidal current $\mathrm{I}(\mathrm{t})$ passes through the thermoresistive probe. A heat flux $\mathrm{P}_{\text {Joule }}$ at pulsation $2 \omega$ is dissipated in the probe generating a temperature variation $\mathrm{T}_{2 \omega}$ at the same pulsation. The thermoresistive probe resistance is then modulated at $2 \omega$. Finally, according to Ohm's law, the tip voltage is modulated at $3 \omega$ and its amplitude can be expressed as[16]:

$$
\left(V_{3 \omega}\right)_{\text {Tip }}=K_{a m p l i} \frac{R_{T i p} \alpha_{T i p} I_{0}}{2}\left\langle T_{2 \omega}\right\rangle
$$

where $K_{\text {ampli }}$ is the amplification system gain, $\mathrm{I}_{0}$ the amplitude of the $\omega$ pulsation current supplying the probe and $\left\langle T_{2 \omega}\right\rangle$ the mean temperature variation amplitude over the tip length $\mathrm{L}_{\text {Tip. }}$ The probe is included in a Wheatstone bridge connected to an amplification system in order to reduce the influence of the other harmonics and amplify the $3 \omega$ signal. Experimentally, a lock-in measurement of the $3 \omega$ tip voltage $\left(\mathrm{V}_{3 \omega}\right)_{\text {Tip }}$ is made during each scan in contact with a sample. At the end of a scan, we assess a topographic image and a $\left(\mathrm{V}_{3 \omega}\right)_{\text {Tip }}$ thermal image. We can then deduce a $\left\langle T_{2 \omega}\right\rangle$ tip temperature variations map and then an equivalent tip-sample thermal resistance $\mathrm{R}_{\text {eq. }}$. Indeed, when the tip comes into contact with a material, a heat flow goes from the tip to the sample and this flow depends on the sample thermal conductance. Consequently, the variations of the tip temperature $\left\langle T_{2 \omega}\right\rangle$ depend on the equivalent thermal resistance $\mathrm{R}_{\mathrm{eq}}$ between the tip and the sample. The more conductive the sample, the lower the $2 \omega$ thermal variations. This configuration, called $3 \omega-\mathrm{SThM}$, is hence 
sometimes also called conductivity contrast imaging. More details about the experimental setup can be found in [16].

In our case, the sample is made of a NW carpet and the tip contacts the NWs on top of them (fig. 1). The heat flux then propagates along the NW. Then, modelling the thermal exchanges between tip and sample by thermal resistances, $\mathrm{R}_{\text {eq }}$ can be likened to a contact resistance $\mathrm{R}_{\mathrm{c}}$ in serie with the tip to NW constriction resistance and the thermal resistance $\mathrm{R}_{\mathrm{NW}}$ of the NW contacted by the tip:

$$
R_{e q}=R_{c}+R_{T i p-N W}+R_{N W} \cdot(2)
$$

Here, we do not take into account the NW to substrate constriction resistance since it is negligible in comparison with the other thermal resistances[6]. Concerning the tip to NW thermal resistance, it depends on the NW diameter/thermal exchange radius ratio and must be evaluated for each tip and each sample. The samples we analyse are classically made of NWs embedded in a $\mathrm{SiO}_{2}$ matrix whose thermal conductivity is known. The contact resistance $\mathrm{R}_{\mathrm{c}}$ depends on the tip and the sample studied but also on the atmospheric conditions. Then, a specific procedure is necessary to evaluate $R_{c}$ for each sample. It is considered constant on the whole thermal image and can then be evaluated from the $3 \omega$-SThM signal measured on the $\mathrm{SiO}_{2}$ part of the sample. Finally, the NW thermal conductivity can be deduced from the thermal conduction in the NW by measuring the $3 \omega$ voltage on the NW section. In the case of the samples studied here, the thermal conductivity of the NW is expected to be higher than the one of the matrix and the substrate is a highly thermally conductive thick Si substrate which can be considered as a semi-infinite medium behaving as a heat sink. Then, a simple 1D 
conduction model can be applied to the thermal transport along the NW with $R_{N W}=\frac{1}{\lambda_{N W}} \frac{L}{S}$

. The thermal conductivity of the NW is then given by:

$$
\lambda_{N W}=\frac{L}{S} \times \frac{1}{R_{e q}-R_{T i p-N W}-R_{c}}
$$

where L and S are respectively the NW length and cross section. We have successfully applied this technique to study the thermal conductivity of organic and inorganic NWs $[6,21,22]$.

Let us underline that, for a sample constituted of several NWs, this experimental method enables to simultaneously measure $\mathrm{R}_{\mathrm{eq}}$ on each $\mathrm{NW}$ in the thermal image. In the following sections, the equivalent thermal resistance values are deduced from the mean value measured on 30 to 50 locations either on the matrix surface (to evaluate $R_{c}$ ) or on the NWs top surface (to evaluate $\mathrm{R}_{\mathrm{NW}}$ ). Then it enables to do a statistical data processing, hence to deduce a mean thermal conductivity and the associated standard deviation, once the value of the contact thermal resistance $\mathrm{R}_{\mathrm{C}}$ has been determined. The uncertainty on the thermal resistances is evaluated from the standard deviation of the $3 \omega$ voltage measured on the 30 to 50 locations whereas the uncertainty on the thermal conductivity also takes into account the dispersion on the length and section of the NWs.

Let us note that the experimental set-up enables to work from atmospheric pressure to a $10^{-5}$ Torr vacuum. In our classical functioning conditions, the probe current amplitude is around $1 \mathrm{~mA}$, its frequency is of $1 \mathrm{kHz}$ and we work under atmospheric conditions. The acquisition time at each position depends on the lock-in amplifier time constant which itself depends on the current frequency. Typically, with a $1 \mathrm{kHz}$ current frequency, the acquisition time for a $256 \times 256$ points image is less than 10 minutes. The thermal exchange radius has been experimentally evaluated to $100 \mathrm{~nm}$ and $175 \mathrm{~nm}$ for the tips used respectively for Ge NWs (section III) and Si NWs (section IV). 


\section{THERMAL CONDUCTIVITY OF HETEROSTRUCTURED GE NANOWIRES}

The first kind of sample is an ordered array of Ge NWs obtained by top-down etching in a n-type (111) Ge substrate. The <111>-NWs were achieved by combining electron beam lithography and reactive ion etching. The patterns consist of $330 * 120 \mu^{2}$ matrix defined by polygon features of $100 \mathrm{~nm}$ diameter and a $300 \mathrm{~nm}$ pitch. The deep etch of the patterned substrate was realized by reactive ion etching inductance coupled plasma RIE-ICP up to $1 \mu \mathrm{m}$ depth. The resulting features are defined by nanopillars with steep edges and diameters ranging from 220 to $460 \mathrm{~nm}$. The nanostructures were finally cleaned in hot aceton $\left(50^{\circ} \mathrm{C}\right)$ for a few minutes to remove all residues. Various diameters of NWs are available on a unique sample by varying the electron dose, offering the possibility to investigate the effect of NW diameter on the thermal conductivity (others parameters being equal). After synthesis, Ge NWs are embedded in a hardening hydrogen silsesquioxane resist (HSQ) followed by a baking at $500^{\circ} \mathrm{C}$. With this process described in [8,9], a phase transformation occurs heterogeneously along the NW length, on (115) shear bands, i.e. at $39^{\circ}$ from the (111) surface plane. The NWs exhibit several $2 \mathrm{H}$ domains with a specific orientation relationship between the parent $3 \mathrm{C}$ phase and the $2 \mathrm{H}$ domains with $(110)_{3 \mathrm{C}} / /(0001)_{2 \mathrm{H}}$. Figure 2 gives an example of a heterostructured Ge NWs sample.

For 3 $\omega$-SThM scanning, the surface of the sample constituted of embedded NWs in silica is planarized using a chemical mechanical polishing (CMP) process with a colloidal silica suspension. 


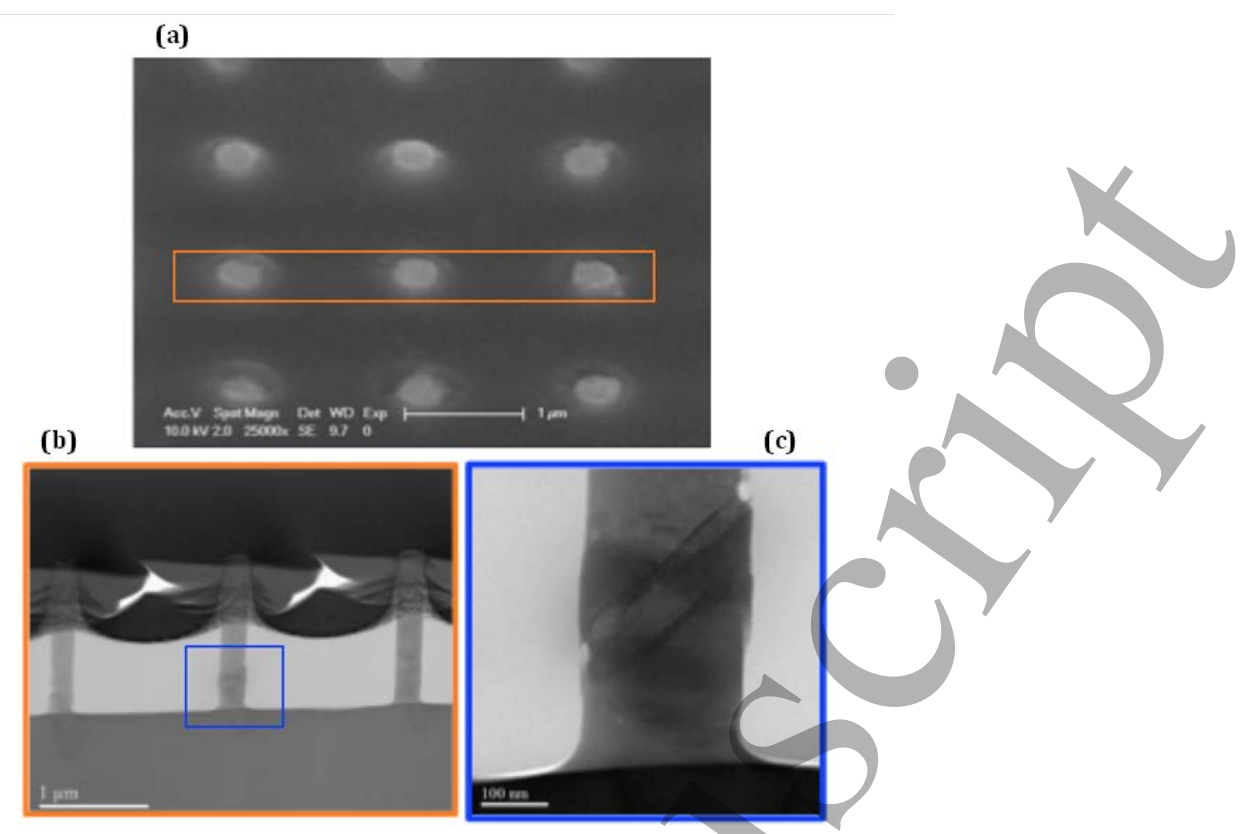

Figure 2. (a) tilted SEM image of one sample showing the nanowires embedded in the HSQ resist after surface polishing, (b) low magnification TEM view of a TEM lamellae with 3 Ge NWs. Such lamellae was obtained by etching around a row of nanowires such as illustrated by the orange box in A, (c) TEM bright field micrograph of the bottom part of the nanowire localised by the blue square in B. Scale bar in (a) and (b) is $1 \mu \mathrm{m}$. Scale bar in (c) is $100 \mathrm{~nm}$.

In [11], the authors have presented theoretical investigations on the interfacial thermal conductance in polytype $3 \mathrm{C} / 2 \mathrm{H}$ Ge interfaces. Using ABCM (adiabatic bond charge model), they studied the effects of the crystal orientation and of the main phonon modes involved in heat transfer. They conclude that such allotrope interfaces should be a promising option to reduce the thermal conductance, in particular in systems with many interfaces such as the NWs described in this paper. In addition, among the 4 different interface orientations they have studied, the lowest conductance has been obtained for the interface orientation identical to the one of our NWs. The main advantage of the sample studied in this section is the possibility to assess different diameters on the same sample. An example of $3 \omega$-SThM 
topographic and thermal images obtained NWs with $400 \mathrm{~nm}$ and $220 \mathrm{~nm}$ diameters is presented in figure 3. We can easily localize the NWs due to a different thermal contrast between the NWs and the matrix. Let us underline also a bright circle surrounding the NWs which we can explain by the fact that the NWs protrude from the matrix and therefore, when passing from the matrix towards a NW, the tip begins contacting the NW by its side and not by its end. The thermal exchange is then totally different and does not correspond to our tip thermal model anymore. Then, we will not consider this part of the NW in the $3 \omega$ voltage and hence in the thermal resistance measurements.

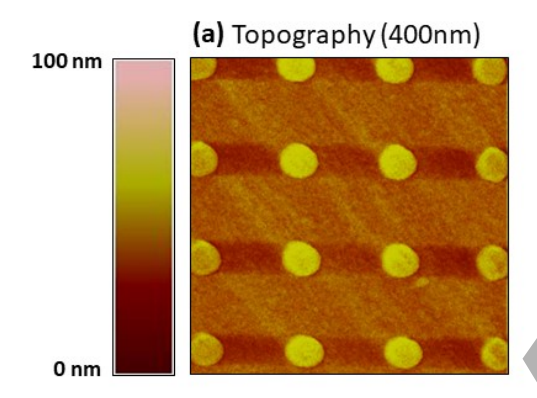

(c) $3 \omega-\operatorname{SThM}(400 \mathrm{~nm})$

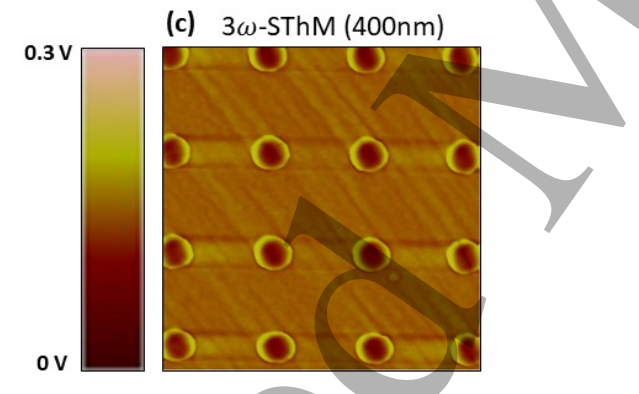

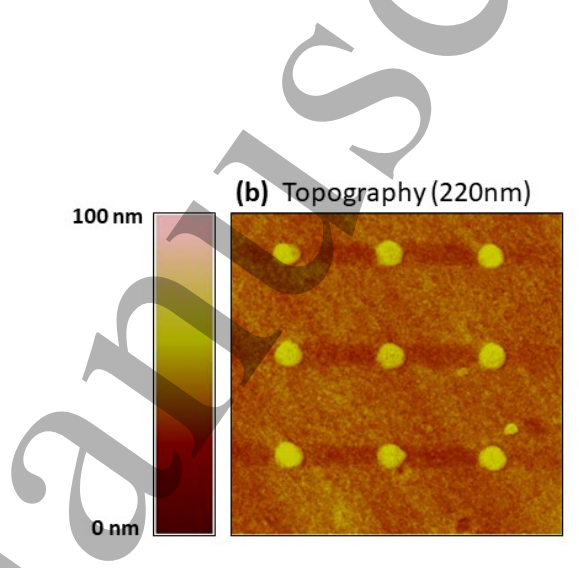

(d) $3 \omega-\operatorname{SThM}(220 \mathrm{~nm})$

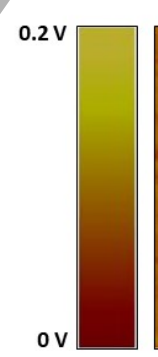

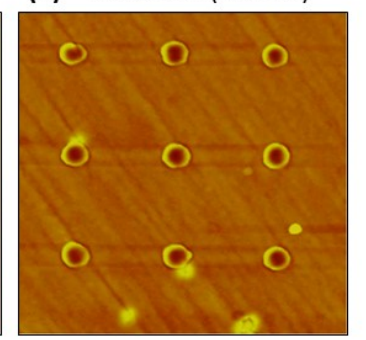

Figure 3. $3 \omega$-SThM images $(5 \mu \mathrm{m} \times 5 \mu \mathrm{m})$ of $3 \mathrm{C} / 2 \mathrm{H}$ Ge NWs: (a) topographical $400 \mathrm{~nm}$ diameter image, (b) topographical $220 \mathrm{~nm}$ diameter image, (c) $400 \mathrm{~nm}$ diameter thermal conductivity contrast image, (d) 220nm diameter thermal conductivity contrast image.

Since the contact exchange radius has been experimentally estimated to $100 \mathrm{~nm}$, for each NW diameter, we can evaluate the tip to NW constriction resistance $\mathrm{R}_{\text {Tip-NW[}}[6]$. From the $3 \omega$ SThM thermal images, we can estimate the value of the contact resistance $R_{c}$ measured on the matrix : $R_{c}=(0.91 \pm 0.04) \times 10^{6} \mathrm{~K} / \mathrm{W}$. Then, we can deduce the $\mathrm{NW}$ thermal resistance $\mathrm{R}_{\mathrm{NW}}$ from 
the $3 \omega$ voltage measured on the whole section of the NW (excluding the bright circle part) which increases from $(1.08 \pm 0.02) \times 10^{6} \mathrm{~K} / \mathrm{W}$ to $(1.69 \pm 0.04) \times 10^{6} \mathrm{~K} / \mathrm{W}$ when the NW diameter decreases from $440 \mathrm{~nm}$ to $220 \mathrm{~nm}$. We can finally estimate the value of the thermal conductivity for each diameter. Let us note that the standard deviation on the thermal conductivity value is low because the dispersion on the measured NW thermal resistance is low but also because the length and section of the NWs are quite homogeneous. Our experimental results are compared in figure 4 with theoretical values obtained for homogeneous 3C Ge NWs[23,24].

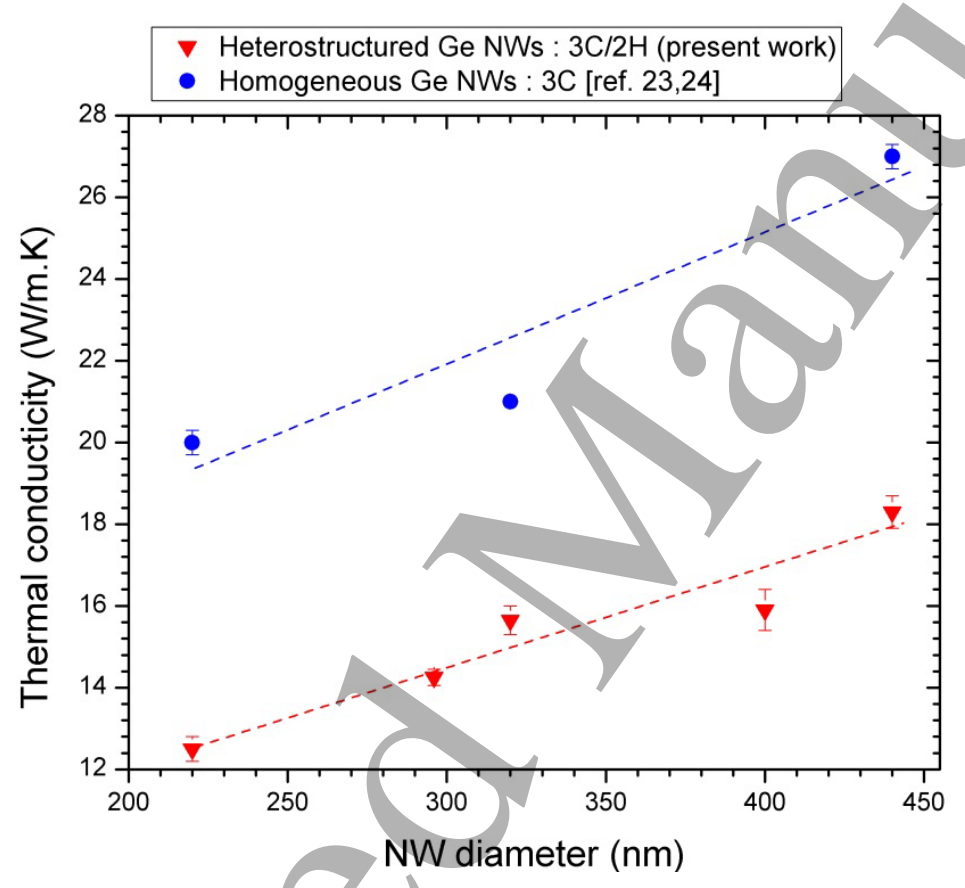

Figure 4. Thermal conductivity of $3 \mathrm{C} / 2 \mathrm{H}$ Ge NWs as a function of diameter. The dashed lines are drawn to guide the eye.

First, the results evidence a thermal conductivity reduction in NWs compared to their counterpart Ge bulk whose thermal conductivity is $60 \mathrm{~W} / \mathrm{m} . \mathrm{K}$. Secondly, we also note a thermal conductivity reduction when reducing the diameter of the NWs for both the homogeneous and heterogeneous NWs. This behavior was well-known for homogeneous NWs $[3,16,25]$ but we have experimentally checked that we observe the same behavior in 
heterogeneous NWs. Finally, the comparison between both kinds of NWs clearly shows a huge reduction of the thermal conductivity when the NWs are heterostructured, up to $66 \%$ for the smallest ones. This reduction can be ascribed to the heterostructuration but also to other phenomena such as roughness or porosity[23], since the homogeneous NWs reveal to present a low roughness, which is not in favor of a thermal conductivity reduction. In heterogeneous NWs, phase transformation locally increases the roughness induced by the shear stresses and this effect is all the more pronounced that the NW diameter is small. That is why here, the thermal conductivity reduction can be partly attributed to an increasing roughness when the NW diameter is reduced.

Next part will hence investigate the influence of the sole heterostructuration effect.

\section{THERMAL CONDUCTIVITY OF HETEROSTRUCTURED SI NANOWIRES}

One must note that the phase transformation process can be applied in Si NWs up to $1000^{\circ} \mathrm{C}$. The number and size of the $2 \mathrm{H}$ domains evolve as a function of temperature. The effect of the heterostructuration was thus studied on random top-down etched Si NWs transformed at various temperatures. The nanowires exhibit a diameter of around $150 \mathrm{~nm}$ and an initial length of $1 \mu \mathrm{m}$. After CMP the final measured lengths varied from $220 \mathrm{~nm}$ to 380 nm (see table 2).

In [10], Raya-Moreno et al have calculated the second and third order interatomic force constants and resolved the Boltzmann Transport Equation to estimate the thermal conductivity of cubic and hexagonal Si NWs and they have shown a reduction of the thermal conductivity for hexagonal NWs by a factor around 2 depending on the NW diameter. The reduction is expected to be more pronounced for diameters between 100 and $150 \mathrm{~nm}$. The NWs presented here should then be very good candidates since they offer various advantages 
to optimally reduce the thermal conductivity: a $150 \mathrm{~nm}$ diameter, $2 \mathrm{H}$ domains and $3 \mathrm{C} / 2 \mathrm{H}$ interfaces.

After $3 \omega$-SThM measurements, the samples have been analyzed by TEM to evaluate their total length (after polishing) and also the $2 \mathrm{H}$ domains mean length as well as the number of $2 \mathrm{H}$ domains. Values are reported in table 2. We also indicate the $2 \mathrm{H}$ length/NW length ratio which corresponds to the $2 \mathrm{H}$ volume fraction and a normalized number $\mathrm{n}_{2 \mathrm{H}}^{*}$ of $2 \mathrm{H}$ domains which corresponds to the number of $2 \mathrm{H}$ domains divided by the NW length $\left(\mathrm{n}^{*}{ }_{2 \mathrm{H}}=\mathrm{n}_{2 \mathrm{H}} / \mathrm{L}_{\mathrm{NW}}\right)$. Indeed, the number of $2 \mathrm{H}$ domains for the different samples cannot be compared if the NWs have different lengths, which is the case after polishing.

\begin{tabular}{|l|l|l|l|l|}
\hline Annealing & 600 & 700 & 900 & 1000 \\
temperature $\left({ }^{\circ} \mathrm{C}\right)$ & & & & \\
\hline $\mathrm{L}_{\mathrm{NW}}(\mathrm{nm})$ & 380 & 220 & 320 & 250 \\
\hline $\mathrm{L}_{2 \mathrm{H}}(\mathrm{nm})$ & 44 & 46 & 75 & 68 \\
\hline $\mathrm{n}_{2 \mathrm{H}}$ & 1.61 & 1.23 & 2.13 & 2.56 \\
\hline $\mathrm{L}_{2 \mathrm{H}} / \mathrm{L}_{\mathrm{NW}}$ & 0.12 & 0.21 & 0.23 & 0.27 \\
\hline $\mathrm{n}^{*}{ }_{2 \mathrm{H}}\left(\mu \mathrm{m}^{-1}\right)$ & 4.23 & 5.59 & 6.66 & 10.24 \\
\hline
\end{tabular}

Table 2. NW structural properties for each annealing temperature.

The sample processed at $500^{\circ} \mathrm{C}$ is not presented in this table since it presents almost no phase transformation and most of the NWs (more than 90\%) are then homogeneous 3C NWs. Very few transformed NWs only exhibit 1 or 2 domains which are very thin and do not extend over the full diameter of the NWs (see images in [9]). This $500^{\circ} \mathrm{C}$-sample can then be considered as a reference. For samples processes at $600^{\circ} \mathrm{C}$, more than $65 \%$ of the NWs are transformed and the $2 \mathrm{H}$ phase involves $12 \%$ of the NW length. At $700^{\circ} \mathrm{C}$, almost all the NWs are transformed. The NWs are quite short, then, if we compare with the $600^{\circ} \mathrm{C} \mathrm{NWs,} \mathrm{the}$ 
absolute $2 \mathrm{H}$ length is comparable but the $2 \mathrm{H}$ volume fraction $\left(\mathrm{L}_{2 \mathrm{H}} / \mathrm{L}_{\mathrm{NW}}\right)$ is much higher, passing from 0.12 to 0.21 as indicated in table 2. Similarly, the number of domains is smaller but it increases if we consider its normalized value $n^{*}{ }_{2 \mathrm{H}}$. Finally, for 900 and $1000^{\circ} \mathrm{C}$ annealing temperatures, the $2 \mathrm{H}$ volume fraction slightly increases and the relative normalized number of domains $\mathrm{n}_{2 \mathrm{H}}$ increases in a more pronounced manner (TEM images of the various samples are given in the supplementary materials). Therefore, when increasing the annealing temperature, the number or domains continuously increases while the relative $2 \mathrm{H}$ domain length rapidly increases between 500 and $700^{\circ} \mathrm{C}$ but then remains quite constant for annealing temperatures above $700^{\circ} \mathrm{C}$.

Figure 5 presents the topographical and thermal images of one of the samples for a $700^{\circ} \mathrm{C}$ annealing temperature. The NWs are almost poorly visible/in the topographical image which indicates that, contrary to the Ge NWs, the Si NWs do not protrude from the matrix. Instead, in the thermal images, the 150nm diameter NWs are clearly distinguished with a good thermal conductivity contrast with the matrix. From the thermal images obtained for the different samples, we could deduce the NW thermal conductivity. For these samples, the thermal exchange radius has been experimentally evaluated to $175 \mathrm{~nm}$. Taking into account this value and the 150nm NW diameter, the tip to NW constriction resistance can be neglected in equations (2) and (3). The contact resistance has been evaluated on the matrix and the NW thermal resistance $R_{N W}$ was then deduced: it increases from $(0.41 \pm 0.04) \times 10^{6} \mathrm{~K} / \mathrm{W}$ to $(0.98 \pm 0.04) \times 10^{6} \mathrm{~K} / \mathrm{W}$ when the annealing temperature increases from 500 to $1000^{\circ} \mathrm{C}$. 
(a) Topography $\left(700^{\circ} \mathrm{C}\right)$

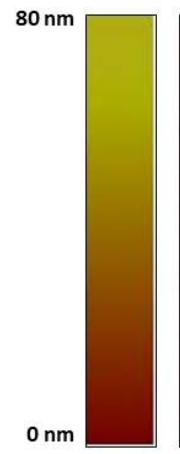

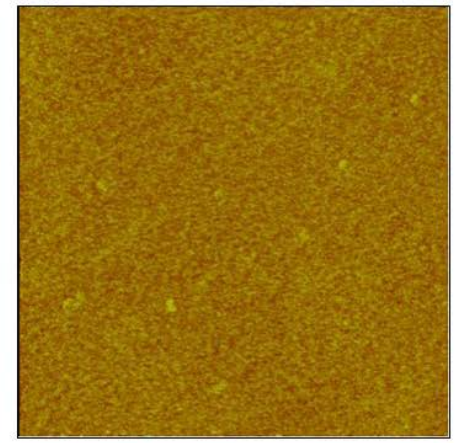

(b) $\quad 3 \omega-\operatorname{SThM}\left(700^{\circ} \mathrm{C}\right)$

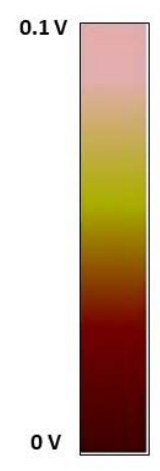

(b) $3 \omega\left(\operatorname{sThM}(70)^{\circ} \mathrm{C}\right.$

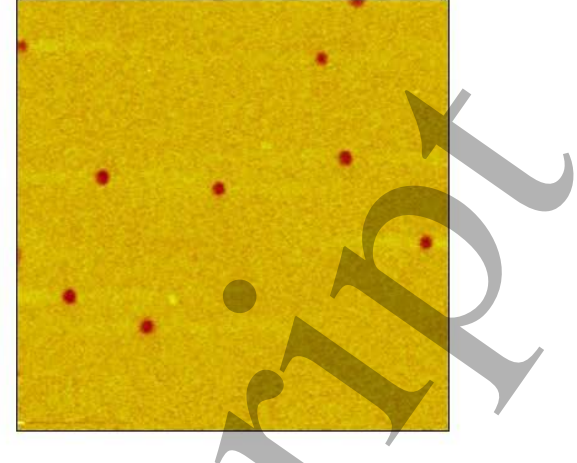

Figure 5. $3 \omega$-SThM images $(5 \mu \mathrm{m} \times 5 \mu \mathrm{m})$ of $150 \mathrm{~nm}$ diameter $3 \mathrm{C} / 2 \mathrm{H}$ Si NWs: (a) topographical image, (b) thermal conductivity contrast image. These images are for a $700^{\circ} \mathrm{C}$ annealing temperature.

For each annealing temperature, taking account the NW length measured afterwards and presented in table 2, we present, in figure 6(a), the mean thermal conductivity evaluated on around thirty NWs. Let us note that the standard deviation on the thermal conductivity value is higher than for Ge NWs, mainly because of a higher dispersion on the length and section of the NWs. For the $500^{\circ} \mathrm{C}$ sample, which presents almost no phase transformation and is then considered as a reference sample, we have identified a $46 \pm 4 \mathrm{~W} \cdot \mathrm{m}^{-1} \cdot \mathrm{K}^{-1}$ thermal conductivity value. This value identified by $3 \omega-$ SThM is in good agreement with values obtained by simulations for 3C 150nm diameter Si NWs[24] or by experimental measurements on other NWs[26] and offers a large reduction in comparison with the $150 \mathrm{~W} / \mathrm{m} . \mathrm{K}$ bulk value.

Then, when the annealing temperature increases from 500 to $1000^{\circ} \mathrm{C}$, we first observe a strong thermal conductivity reduction when passing from 500 to $700^{\circ} \mathrm{C}$, reaching more than $60 \%$. Now, when increasing again the annealing temperature from 700 to $1000^{\circ} \mathrm{C}$, then the thermal conductivity is quite constant and its identified value is less than $20 \mathrm{~W} / \mathrm{m} . \mathrm{K}$. In [10], the authors have evaluated the $\lambda_{2 \mathrm{H}} / \lambda_{3 \mathrm{C}}$ ratio for Si NWs. Using the $\lambda_{3 \mathrm{C}}$ measured on the $500^{\circ} \mathrm{C}$ annealed sample, we can deduce the simulated $\lambda_{2 \mathrm{H}}$ value for $150 \mathrm{~nm}$ diameter NWs around 23 $\mathrm{W} \cdot \mathrm{m}^{-1} \cdot \mathrm{K}^{-1}$. It is worth noting that the thermal conductivity we have identified for the $2 \mathrm{H} / 3 \mathrm{C}$ 
samples processed at $700^{\circ} \mathrm{C}, 900^{\circ} \mathrm{C}$ and $1000^{\circ} \mathrm{C}$ is slightly lower than the theoretical value predicted for homogeneous 2H NWs.

Through heterostructuration, two phenomena can be responsible for the thermal conductivity reduction: the increasing number of thermal barriers along the NW and the $2 \mathrm{H}$ domain length (or volume fraction) because of the smaller thermal conductivity of $2 \mathrm{H} \mathrm{Si}$ as compared to 3C Si[10]. Figure 6(a) presents the $2 \mathrm{H}$ volume fraction for the various annealing temperature, in addition to the mean thermal conductivity. We can observe a good correlation between the thermal conductivity and the $2 \mathrm{H}$ volume fraction. Indeed, between 500 and $700^{\circ} \mathrm{C}$, the $2 \mathrm{H}$ volume fraction strongly increases while the thermal conductivity is strongly reduced but for higher annealing temperature both quantities remain quite constant. In figure 6(b) we have thus plotted $1 / \lambda_{\mathrm{NW}}$ as a function of the volume fraction. The behaviour is quite linear which highlights the correlation between both quantities.
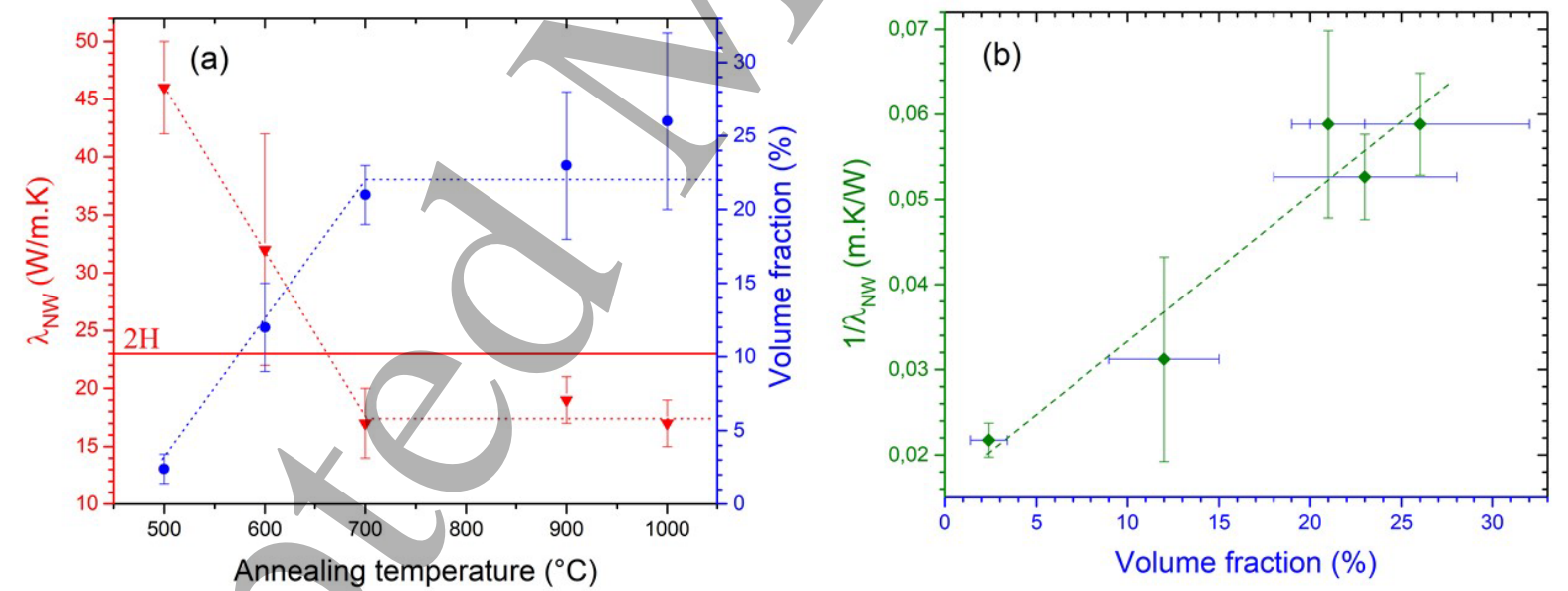

Figure 6. 3C/2H Si NWs: (a) NW thermal conductivity and volume fraction as a function of annealing temperature and (b) inverse of NW thermal conductivity as a function of volume fraction. The dashed lines are drawn to guide the eye.

As for the mean normalized number of $2 \mathrm{H}$ domains, it constantly increases when the annealing temperature increases as illustrated in figure 7(a). Since the NW thermal 
conductivity value is quite constant for annealing temperatures above $700^{\circ} \mathrm{C}$, it seems that the fragmentation of $2 \mathrm{H}$ domains is not a key parameter in the thermal conductivity reduction. Figure $7(\mathrm{~b})$ presents $1 / \lambda_{\mathrm{NW}}$ as a function of the mean normalized number of $2 \mathrm{H}$ domains and does not show any obvious correlation between these parameters.
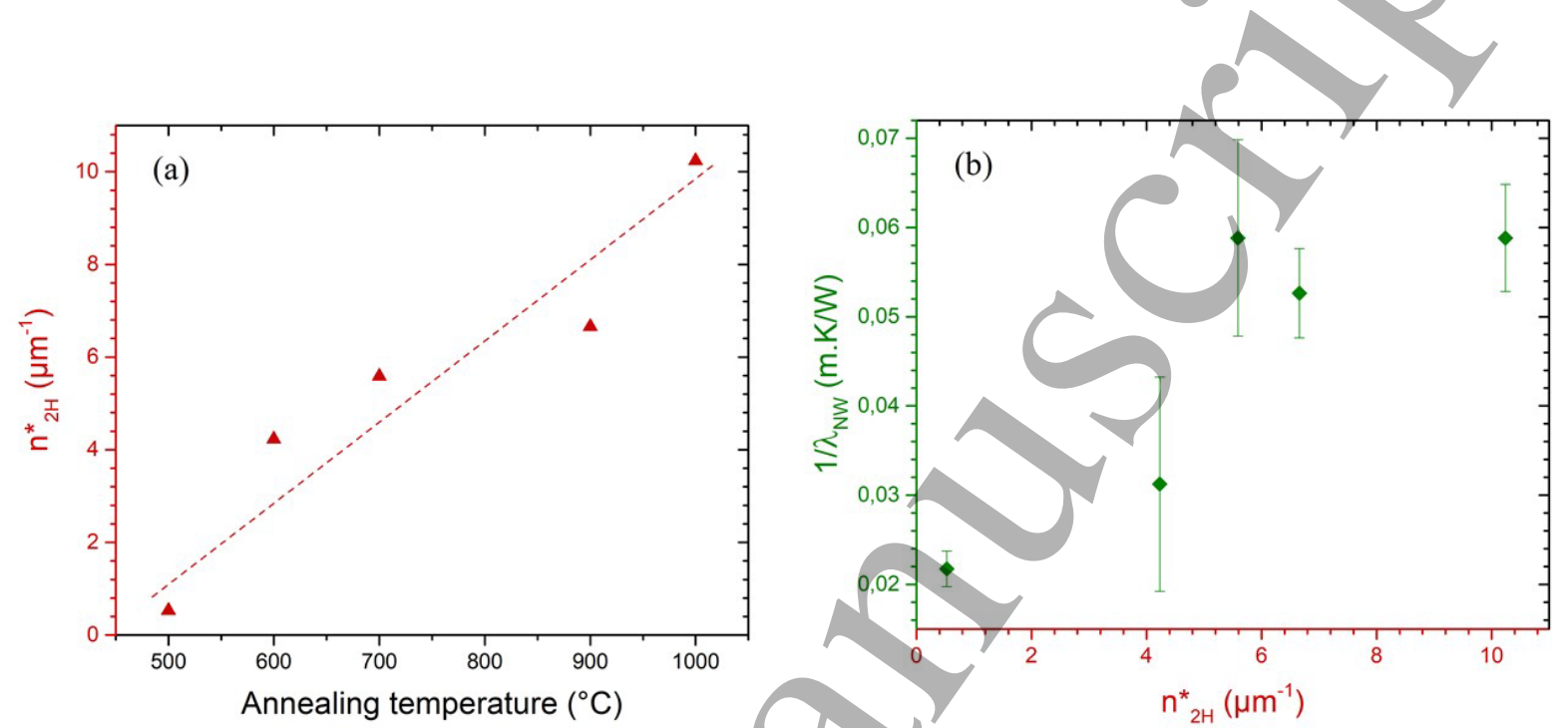

Figure 7. 3C/2H Si NWs: (a) normalized number of domains (number of $2 \mathrm{H}$ domains divided by the NW length) as a function of annealing temperature and (b) inverse of NW thermal conductivity as a function of normalized number of domains. The dashed line in (a) is drawn to guide the eye.

This observation leads to the conclusion that even if the number of domains (i.e. the number of thermal barriers) may be responsible for a phonon scattering, which is highlighted by the fact that we can reach a thermal conductivity lower than the $23 \mathrm{~W} / \mathrm{m} . \mathrm{K}$ value predicted for $150 \mathrm{~nm}$ diameter homogeneous $2 \mathrm{H} \mathrm{NWs}$, the $2 \mathrm{H}$ domain length is the major factor which controls the reduction of thermal conductivity related to a lower thermal conductivity of the $2 \mathrm{H}$ phase as estimated in [10]. The fragmentation of the $2 \mathrm{H}$ domains does not influence the thermal conductivity reduction as much as the $2 \mathrm{H}$ length.

Finally, the NW thermal resistance $\mathrm{R}_{\mathrm{NW}}$ is constituted of 3 series resistances: the $2 \mathrm{H}$ domain thermal resistance, the $3 \mathrm{C}$ domain thermal resistance and the polytype interface 
resistance. Using the $23 \mathrm{~W} / \mathrm{m} . \mathrm{K} 2 \mathrm{H}$ thermal conductivity predicted in [10] and the the $\lambda_{3 \mathrm{C}}$ measured on the $500^{\circ} \mathrm{C}$ annealed sample, we can hence estimate the polytype interface conductance in the range of $150-400 \mathrm{MW} / \mathrm{m}^{2} . \mathrm{K}$, in good accordance with the order of magnitude of the conductance identified in [11] by theoretical investigations.

\section{CONCLUSION}

We have experimentally demonstrated that polytype heterostructuration of NWs could reduce their thermal conductivity. This effect has been supposedly observed in heterostructured 2H/3C Ge NWs and confirmed in Si NWs, for which a correlation between the fabrication process annealing temperature, which influences the number and the size of 2H domains, and the thermal conductivity reduction has been shown. As a consequence, allotrope heterostructured NWs of group IV semiconductor seem to be very good candidates for thermoelectric applications, especially as these inorganic materials are widely used in electronics and can be doped. We can hence hope that doping heterostructured NWs will enable to reduce the thermal conductivity and improve the electrical conductivity. Next steps will therefore consist in simulating the thermal conductivity of polytype $3 \mathrm{C} / 2 \mathrm{H} \mathrm{Ge}$ and $\mathrm{Si}$ NWs and in studying the influence of doping on the thermal conductivity but also on the electrical parameters in order to possibly improve the figure of merit.

\section{ACKNOWLEDGMENTS}

This work was performed in the framework of the ANR HEXSIGE project (ANR-17-CE0300014-01) funded by the French Agence Nationale de la Recherche.

Samples were performed in micro/nano fabrication facility of $\mathrm{C} 2 \mathrm{~N}$, which is part of the national network Renatech of French clean rooms centers. 
Part of this work was supported by $\mathrm{PhD}$ grant and funding from the LIDEX Nanodesign plateform. 


\section{References}

[1] G. Chen, M.S. Dresselhaus, G. Dresselhaus, J.-P. Fleurial and T. Caillat, International Materials Reviews 48, 45 (203).

[2] X. Chen, Y. Wang, Y. Ma, T. Cui and G. Zou, J. Phys. Chem C 113, 14001 (2009).

[3] A.I. Hochbaum, R. Chen, R. Diaz Delgado, W. Liang, E.C. Garnett, M, Najarian, A. Majumdar, and P. Yang, Nature 451, 163 (2008).

[4] T. Zhang, s. Wu, J. Xu, R. Zheng and G. Cheng, Nano Energy 13, 433 (2015).

[5] D. Davila, A. Tarancón, D. Kendig, M. Fernández-Regúlez, N. Sabaté, M. Salleras, C.

Calaza, C. Cané, I. Gràcia, E. Figueras, J. Santander, A. San Paulo, A. Shakouri and L. Fonseca, J. Elec. Mat. 40, 851 (2011).

[6] S. Grauby, E. Puyoo, J-M. Rampnoux, E. Rouvière, and S. Dilhaire, J. Phys. Chem. C 117, 9025-9034 (2013).

[7] R.E. Algra, M.A. Verheijen, L-F. Feiner, G.G.W. Immink, W.J.P. van Enckevort, E. Vlieg, and E.P.A.M. Bakkers, Nano. Lett. 11, 1259-1264 (2011).

[8] L. Vincent, G. Patriarche, G. Hallais, C. Renard, C. Gardès, D. Troadec and D. Bouchier, Nano. Lett. 14, 4828-4836 (2014).

[9] L. Vincent, D. Djomani, M. Kakhfakh, C. Renard, B. Belier, D. Bouchier and G. Patriarche, Nanotechnology 29,125601 (2018).

[10] M. Raya-Moreno, H. Aramberri, J.A. Seijas-Bellido, X. Cartoixa, and R. Rurali, Appl. Phys. Lett. 111, 032107 (2017).

[11] J. Larroque, P. Dollfus, and J. Saint-Martin, J. Appl. Phys. 123, 025702 (2018).

[12] D. Li, Y. Wu, P. Kim, L. Shi, and P. Yang, Appl. Phys. Lett. 83, 2934 (2003).

[13] L. Shi, D. Li, C. Yu, W. Jang, D. Kim, Z. Yao, P. Kim, and A. Majumdar, J. Heat Trans.-T ASME 125, 881 (2003). 
[14] A.I. Boukai, Y. Bunimovich, J. Tahir-Kheli, J-K. Yu, W.A. Goddard III, and J.R. Heath, Nature 451, 168 (2008).

[15] A.I Persson, Y.K. Koh, D.G. Cahill, L. Samuelson, and H. Linke, Nanolett. 9, 4484 (2009).

[16] E. Puyoo, S. Grauby, J-M. Rampnoux, E. Rouvière, and S. Dilhaire, J. Appl. Phys. 109, 024302 (2011).

[17] L. Shi, J. Zhou, P. Kim, A. Bachtold, A. Majumdar, P.L. McEuen, J. Appl. Phys. 105, 104306 (2009).

[18] M. Hinz, O. Marti, B. Gotsmann, M.A. Lantz, U. Dürig, Appl. Phys. Lett. 92, 043122 (2008).

[19] S. Lefèvre, S. Volz, Rev. Sci. Instrum. 76, 033701 (2005).

[20] E. Puyoo, S. Grauby, J-M. Rampnoux, E. Rouviẹre, and S. Dilhaire, Rev. Sci. Instrum. 81, 073701 (2010).

[21] M. Munoz Rojo, J. Martin, S. Grauby, T. Borca-Tasciuc, S. Dilhaire, and M. MartinGonzalez, Nanoscale 6, 7858 (2014).

[22] M. Munoz Rojo, S. Grauby, J.-M. Rampnoux, O. Caballero-Calero, M. MartinGonzalez, and S. Dilhaire, J. Appl. Phys. 113, 054308 (2013).

[23] P.N. Martin, Z. Aksamija, E. Pop, and U. Ravaioli, Nano Lett. 10, 1120-1124 (2010).

[24] W. Li, and N. Mingo, J. Appl. Phys. 114, 054307 (2013).

[25] Z. Wang, and N. Mingo, Appl. Phys. Lett. 97, 101903 (2010).

[26] G.S. Doerk, C. Carraro, and R. Maboudian, ACS Nano 4, 4908 (2010). 


\section{Table Captions}

Table 1. Pd thermoresitive tip characteristics

Table 2. NW structural properties for each annealing temperature. 


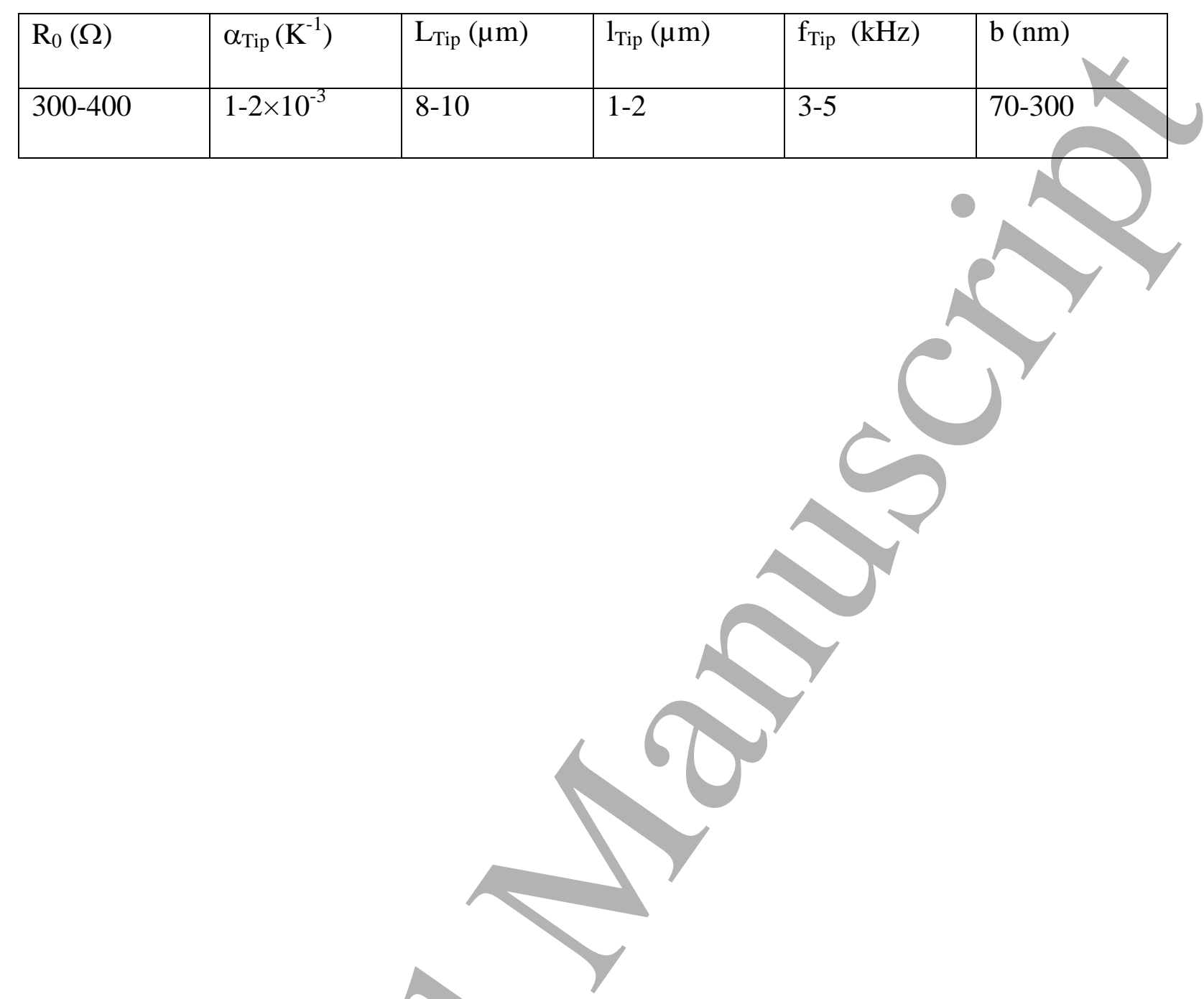

Table1. 


\begin{tabular}{|l|l|l|l|l|}
\hline $\begin{array}{l}\text { Annealing } \\
\text { temperature }\left({ }^{\circ} \mathrm{C}\right)\end{array}$ & 600 & 700 & 900 & 1000 \\
\hline $\mathrm{L}_{\mathrm{NW}}(\mathrm{nm})$ & 380 & 220 & 320 & 250 \\
\hline $\mathrm{L}_{2 \mathrm{H}}(\mathrm{nm})$ & 44 & 46 & 75 & 68 \\
\hline $\mathrm{n}_{2 \mathrm{H}}$ & 1.61 & 1.23 & 2.13 & 2.56 \\
\hline $\mathrm{L}_{2 \mathrm{H}} / \mathrm{L}_{\mathrm{NW}}$ & 0.12 & 0.21 & 0.23 & 0.27 \\
\hline $\mathrm{n}^{*}{ }^{*}\left(\mu \mathrm{m}^{-1}\right)$ & 4.23 & 5.59 & 6.66 & 10.24 \\
\hline
\end{tabular}

Table 2. 


\section{Figure Captions}

Figure 1. Schematic view of the sample and measurement principle: the $<111>$ NWs are grown by top-down etching, then spin coated in HSQ resist which transforms into $\mathrm{SiO}_{2}$ after annealing. The HSQ ensures the phase transformation and the mechanical handling. Red zones along the NWs represent $2 \mathrm{H}$ domains. No transformation could be observed for other crystallographic orientations. The SThM thermoresistive tip scans the surface of the sample. It generates a heat flux on top of the NWs which propagates along them.

Figure 2. (a) tilted SEM image of one sample showing the nanowires embedded in the HSQ resist after surface polishing, (b) low magnification TEM view of a TEM lamellae with $3 \mathrm{Ge}$ NWs. Such lamellae was obtained by etching around a row of nanowires such as illustrated by the orange box in A, (c) TEM bright field micrograph of the bottom part of the nanowire localised by the blue square in B. Scale bar in (a) and (b) is $1 \mu \mathrm{m}$. Scale bar in (c) is $100 \mathrm{~nm}$.

Figure 3. $3 \omega$-SThM images $(5 \mu \mathrm{m} \times 5 \mu \mathrm{m})$ of $3 \mathrm{C} / 2 \mathrm{H}$ Ge NWs: (a) topographical $400 \mathrm{~nm}$ diameter image, (b) topographical $220 \mathrm{~nm}$ diameter image, (c) $400 \mathrm{~nm}$ diameter thermal conductivity contrast image, (d) 220nm diameter thermal conductivity contrast image.

Figure 4. Thermal conductivity of $3 \mathrm{C} / 2 \mathrm{H}$ Ge NWs as a function of diameter. The dashed lines are drawn to guide the eye.

Figure 5. $3 \omega$-SThM images $(5 \mu \mathrm{m} \times 5 \mu \mathrm{m})$ of $150 \mathrm{~nm}$ diameter $3 \mathrm{C} / 2 \mathrm{H}$ Si NWs: (a) topographical image, (b) thermal conductivity contrast image. These images are for a $700^{\circ} \mathrm{C}$ annealing temperature.

Figure 6. 3C/2H Si NWs: (a) NW thermal conductivity and volume fraction as a function of annealing temperature and (b) inverse of NW thermal conductivity as a function of volume fraction. The dashed lines are drawn to guide the eye.

Figure 7. 3C/2H Si NWs : (a) normalized number of domains (number of $2 \mathrm{H}$ domains divided by the NW length) as a function of annealing temperature and (b) inverse of NW thermal conductivity as a function of normalized number of domains. The dashed line in (a) is drawn to guide the eye.

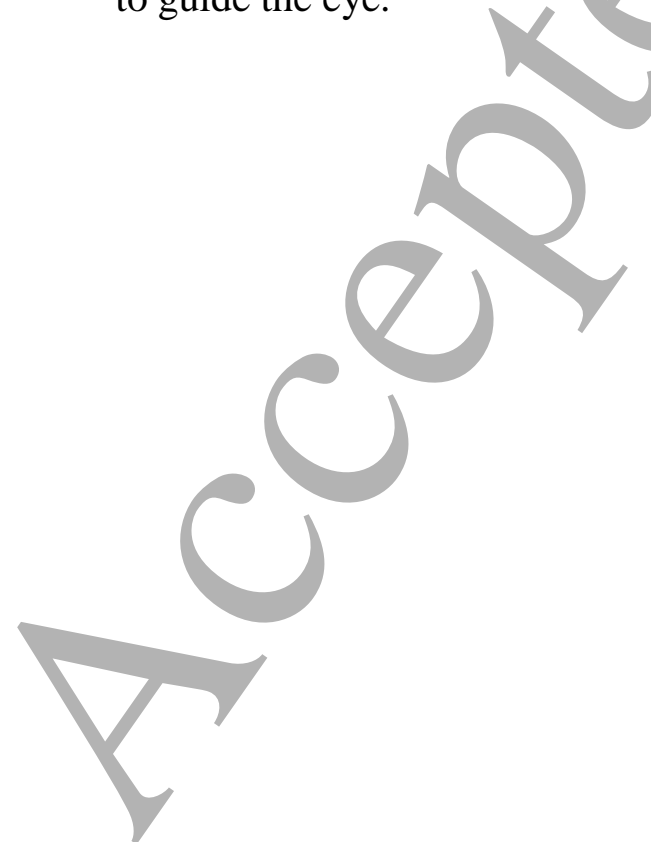




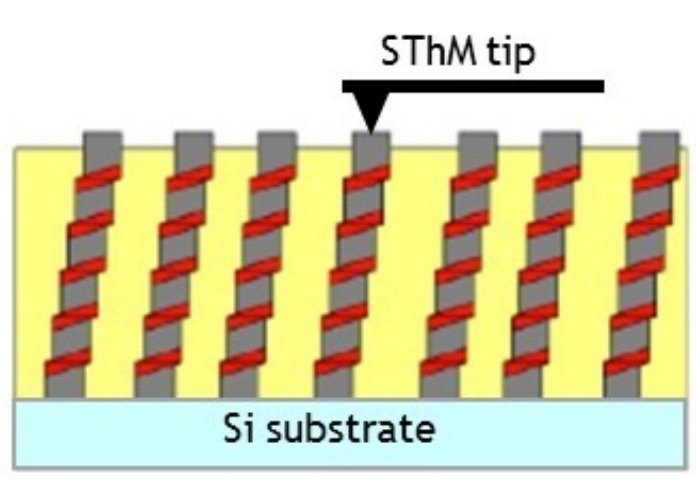

Figure 1 
(a)

(b)

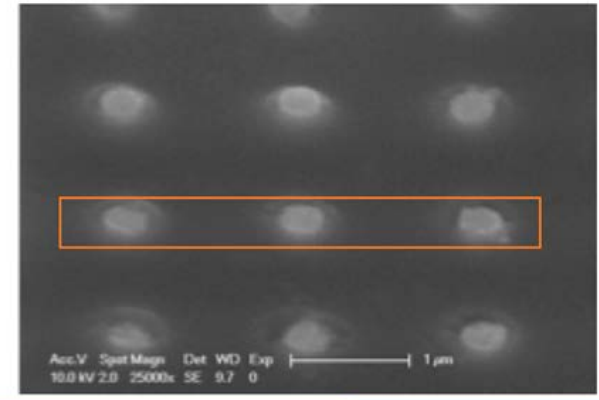

(c)

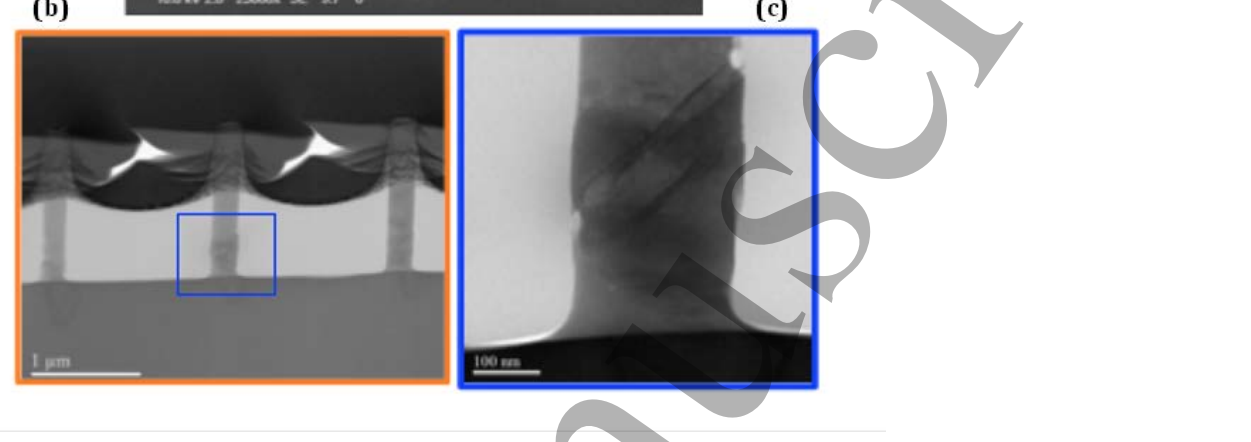

Figure 2 
(a) Topography (400nm)

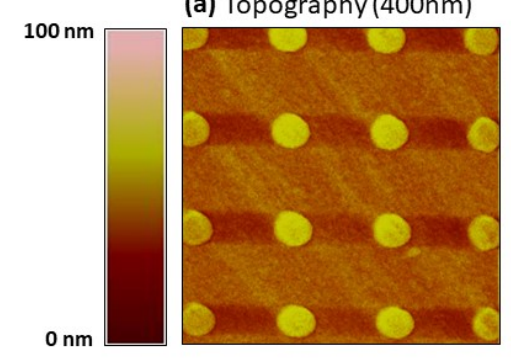

(c) $3 \omega-\operatorname{SThM}(400 \mathrm{~nm})$

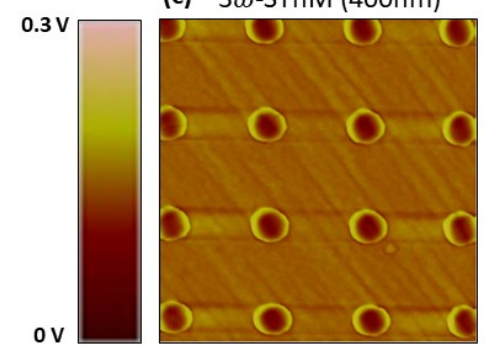

(b) Topography (220nm)

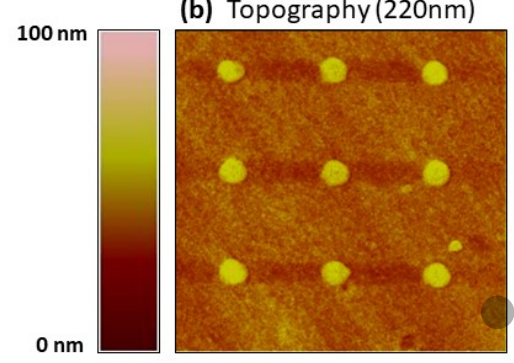

(d) $3 \omega-\operatorname{SThM}(220 \mathrm{~nm})$

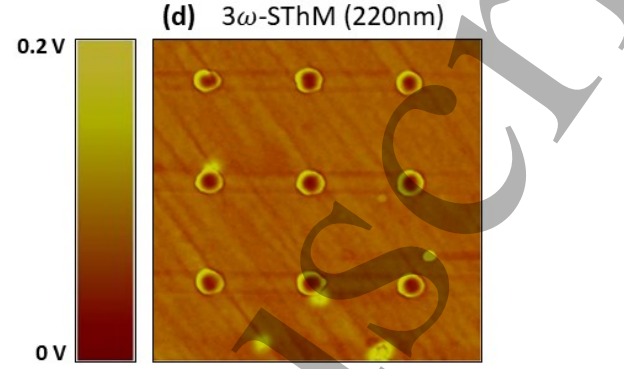

Figure 3

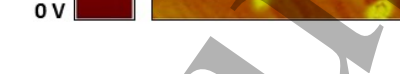




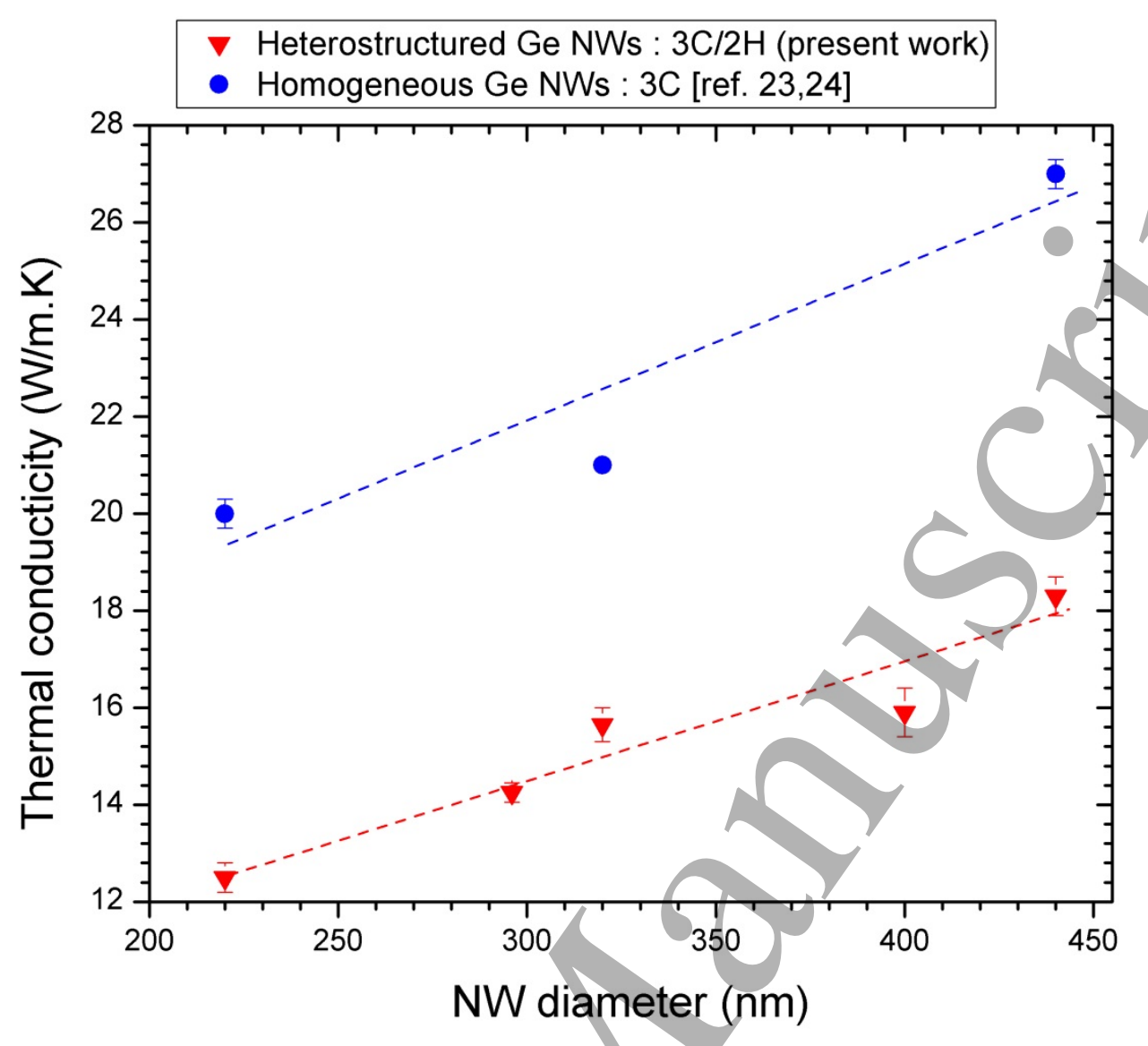

Figure 4

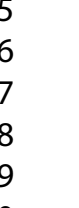


(a) Topography $\left(700^{\circ} \mathrm{C}\right)$

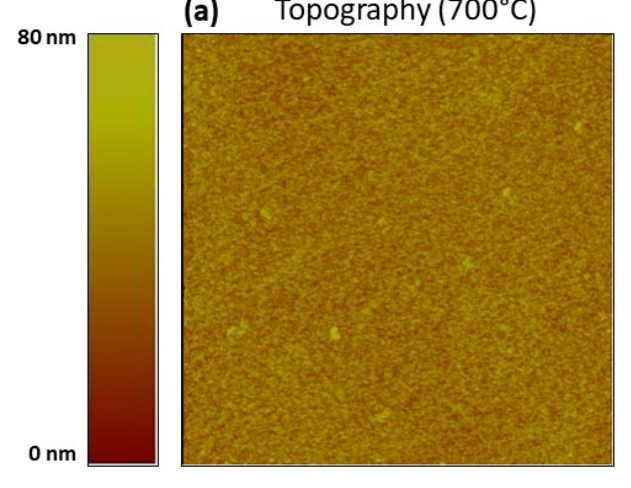

(b) $\quad 3 \omega-\operatorname{SThM}\left(700^{\circ} \mathrm{C}\right)$

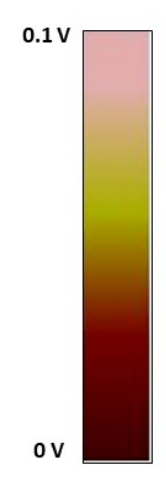

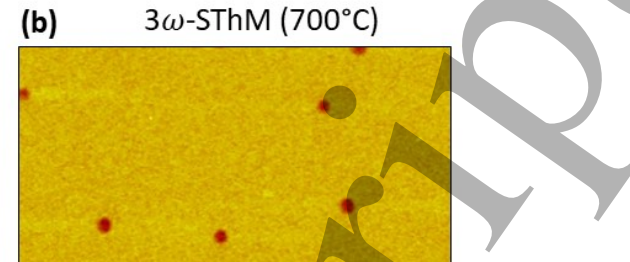

Figure 5

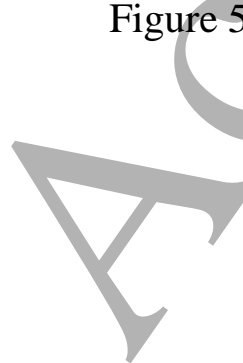



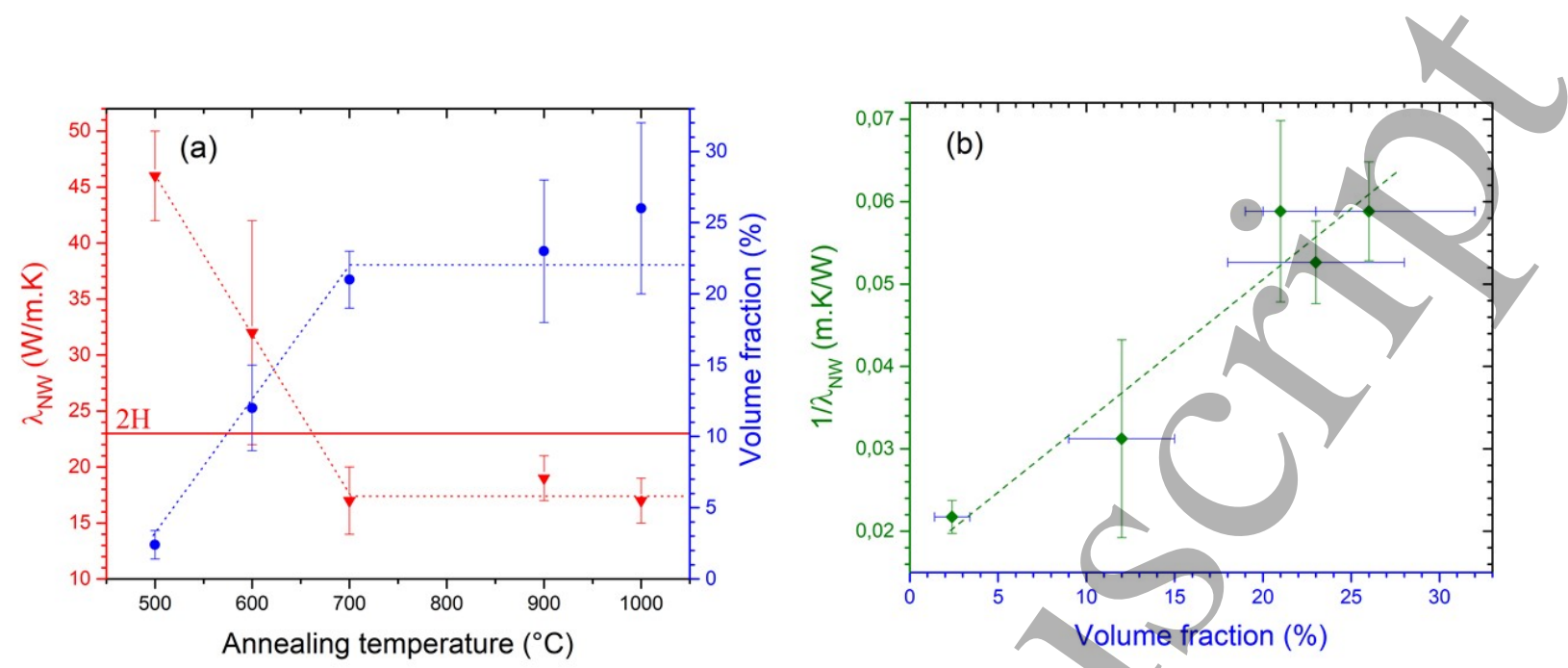

\section{Figure 6}

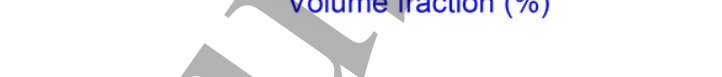



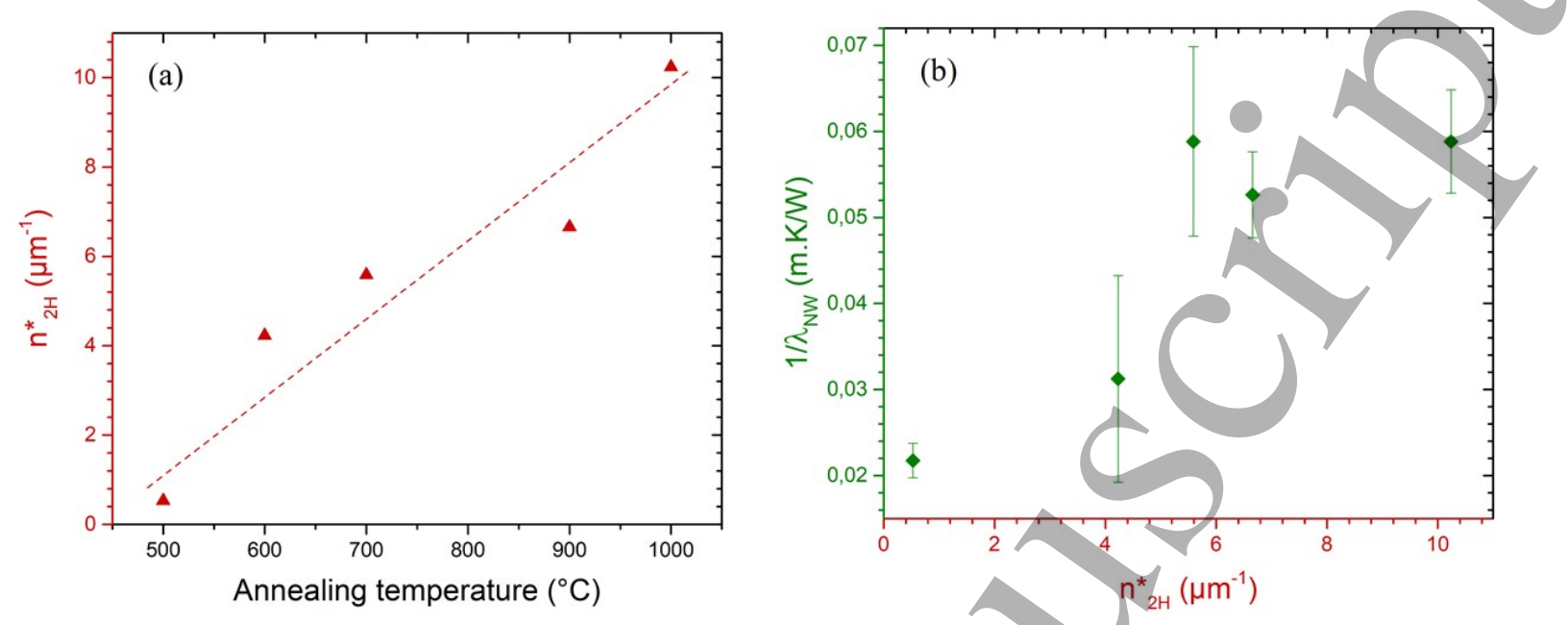

\section{Figure 7}

